\title{
Astragalus polysaccharides decrease proliferation, migration, and invasion but increase apoptosis of human osteosarcoma cells by up-regulation of microRNA-133a
}

\author{
Yanchen $\mathrm{Chu}^{1 *}$, Yuan Fang ${ }^{2 *}$, Jingwei $\mathrm{Chi}^{3}$, Jing $\mathrm{Li}^{4}$, Dongyang Zhang ${ }^{5}$, Yunwen Zou ${ }^{1}$ and \\ Zhijie Wang ${ }^{1}$ \\ ${ }^{1}$ Department of Spinal Surgery, The Affiliated Hospital of Qingdao University, Qingdao, Shandong, China \\ ${ }^{2}$ Department of Joint Surgery, The Affiliated Hospital of Qingdao University, Qingdao, Shandong, China \\ ${ }^{3}$ Key Laboratory of Thyroidism, The Affiliated Hospital of Qingdao University, Qingdao, Shandong, China \\ ${ }^{4}$ Department of Gynaecology and Obstetrics, The Affiliated Hospital of Qingdao University, Qingdao, Shandong, China \\ ${ }^{5}$ Department of Orthopedics, Laixi People's Hospital, Laixi, Shandong, China
}

\begin{abstract}
Osteosarcoma (OS) has a high incidence, malignity, and frequency of recurrence and metastasis. In this study, we aimed to explore the potential anti-cancer effects of Astragalus polysaccharides (APS) on human OS MG63 cells as well as underlying mechanisms. Viability of MG63 cells was assessed by CCK-8 assay to determine the adequate concentration of APS. Then, effects of APS on MG63 cell proliferation, cell cycle distribution, apoptosis, and migration and invasion were analyzed by BrdU incorporation, PI staining, flow cytometry, and transwell assays, respectively. The expression levels of proteins involved in these physiological processes were assessed by western blot analysis. Afterwards, miR-133a level in APS-treated cells was determined by qRT-PCR, and whether APS affected MG63 cells through regulation of miR-133a was determined. Finally, the activation of c-Jun N-terminal protein kinase (JNK) pathway was detected. We found that APS treatment suppressed the viability, proliferation, migration, and invasion of MG63 cells, as well as induced cell apoptosis. Moreover, APS enhanced the expression of miR-133a in MG63 cells. Knockdown of miR-133a reversed the APS treatment-induced MG63 cell proliferation, migration and invasion inhibition, as well as cell apoptosis. Furthermore, APS inactivated JNK pathway in MG63 cells. Knockdown of miR-133a reversed the APS treatment-induced inactivation of JNK pathway in MG63 cells. To conclude, APS repressed proliferation, migration, and invasion while induced apoptosis of OS MG63 cells by up-regulating miR-133a and then inactivating JNK pathway.
\end{abstract}

Key words: Osteosarcoma; Astragalus polysaccharides; Anti-tumor; microRNA-133a; JNK

\section{Introduction}

As the most common aggressive cancer in the human skeletal system, osteosarcoma (OS) is becoming the second leading cause of cancer-related deaths in children and adolescents $(1,2)$. Tumor metastasis is the main reason for the death of patients with OS (3). Before diagnosis, about $15-20 \%$ of OS patients present metastasis, and $40 \%$ of patients will develop metastasis during treatments $(4,5)$. Currently, with the development of surgical removal and multiple-targets therapy, the prognosis of OS has been improved significantly (6). However, $30 \%$ of localized OS and $70 \%$ of metastatic OS still have a poor prognosis (7). Therefore, more effective and suitable therapeutic agents should be identified to further improve the survival of OS.

Astragalus polysaccharides (APS) are the main active ingredients isolated from the root of Astragalus membranaceus (Fisch.) Bunge with diverse bio-activities. For example, Chen et al. (8) showed that APS could protect myocardium in diabetic hamsters by improving myocardial glycolipid metabolic disorder. Liu et al. (9) indicated that APS could protect liver from ionizing radiation-induced injury by reducing oxidative stress in animals. The study

Correspondence: Zhijie Wang: <wangz327@sina.com>

${ }^{*}$ These authors contributed equally to this work. 
from Guo et al. (10) reported that APS could be used as a potential anti-Epstein-Barr virus drug. The antiinflammatory effects of APS have been reported both in vivo and in vitro $(11,12)$. Recently, the anti-cancer activity of APS has been identified, which demonstrated that APS could inhibit liver cancer in murine $\mathrm{H} 22$ hepatocarcinoma model (13). In human hepatocellular carcinoma cells, APS has been found to significantly reduce cell viability and induce apoptosis (14). However, the role of APS in OS remains unclear.

Although the anti-cancer effects of APS have been reported, studies on the underlying mechanisms are limited. MicroRNAs (miRNAs/miRs) are short, non-coding RNAs in eukaryotic cells that play key roles in the regulation of protein synthesis thereby participating in multiple biological processes (15). Numerous miRNAs have been identified to be involved in the progression of OS, acting as oncogenes or tumor suppressors. For example, miR-130b has been found to promote proliferation and inhibit apoptosis of OS cells through regulating the Wnt pathway (16). Conversely, miR-26a has been reported to repress the stem cell-like phenotype and tumor growth of OS cells by targeting Jagged1 (17). Moreover, a previous study reported that APS down-regulated miR-721 and thereby exerted insulin resistance in 3T3-L1 adipocytes (18). Therefore, we hypothesized that APS might affect OS cells through regulation of miRNAs.

In our study, we explored the functional roles of APS in proliferation, apoptosis, migration, and invasion of OS cells. Moreover, the underlying molecular mechanism associated with miRNAs and JNK signaling pathway was investigated.

\section{Material and Methods}

\section{Cell culture and treatment}

Human OS cell line MG63 was obtained from the Institute of Biochemistry and Cell Biology, Chinese Academy of Sciences (China). MG63 cells were maintained in high glucose Dulbecco's modified Eagle's medium (DMEM; Invitrogen, USA) containing 10\% (v/v) fetal bovine serum (Invitrogen) and 1\% (v/v) penicillinstreptomycin (100X, Gibco, Life Technologies, USA) at $37^{\circ} \mathrm{C}$ with $5 \% \mathrm{CO}_{2}$.

APS were obtained from Boster Biology Corporation (China) and dissolved in pure water following the manufacturer's instruction. For APS treatment, MG63 cells were incubated in DMEM containing $0-20 \mathrm{mg} / \mathrm{mL}$ APS at $37^{\circ} \mathrm{C}$ for $24 \mathrm{~h}$.

\section{Cell viability assay}

Viability of MG63 cells after APS treatment was determined by Cell Counting Kit-8 (CCK-8) assay. Briefly, cells were seeded into 96 -well plates with a density of $5 \times$ $10^{3}$ cells per well. After incubation at $37^{\circ} \mathrm{C}$ overnight, the culture medium was replaced by DMEM containing
0-20 mg/mL APS. After stimulation for $24 \mathrm{~h}, 10 \mu \mathrm{L}$ of CCK-8 solution (Dojindo Molecular Technologies, USA) was added to each well, and the plate was maintained at $37^{\circ} \mathrm{C}$ for $1 \mathrm{~h}$ Subsequently, the absorbance of each well at $450 \mathrm{~nm}$ was measured using a Microplate Reader (Bio-Rad, USA). Cell viability (\%) was calculated by average absorbance of APS treatment group/average absorbance of control group $\times 100 \%$.

\section{Cell transfection}

MiR-133a inhibitor and its negative control (NC) were synthesized by GenePharma Co. (China). The sequence of miR-133a inhibitor was 5'-CAGCUGGUUGAAGGGG ACCAAA- $3^{\prime}$. The sequence of NC was $5^{\prime}$-UCACAACC UCCUAGAAAGAGUAGA-3'. For transient transfection, $100 \mathrm{nM}$ miRNAs were transfected into MG63 cells using Lipofectamine 3000 reagent (Invitrogen) following the manufacturer's instructions.

\section{Cell proliferation assay}

Proliferation of MG63 cells was analyzed by 5-bromo2'-deoxyuridine (BrdU) incorporation assay using a Cell Proliferation ELISA kit (Roche, Germany). Briefly, cells were plated in 96-well plates and maintained overnight. Then, after relevant treatments, cells were incubated in BrdU labeling solution for $3 \mathrm{~h}$ at $37^{\circ} \mathrm{C}$, and subjected to recommended protocols from the manufacturer. Finally, the absorbance of each well at $450 / 550 \mathrm{~nm}$ was measured by a Microplate Reader (Bio-Rad).

\section{Cell cycle analysis}

MG63 cell cycle distribution after APS treatment was analyzed using PI staining and flow cytometer. Briefly, MG63 cells were seeded into 24-well plates with a density of $3 \times 10^{4}$ per well. After incubation at $37^{\circ} \mathrm{C}$ overnight, the culture medium was replaced by DMEM containing $10 \mathrm{mg} / \mathrm{mL}$ APS for $24 \mathrm{~h}$. Then, cells in each group were harvested, washed twice with cold phosphate buffered saline (PBS), fixed with $70 \%$ ice-cold ethanol at $-20^{\circ} \mathrm{C}$ overnight, washed twice with cold PBS, incubated with $100 \mathrm{mg} / \mathrm{mL}$ RNase A for $30 \mathrm{~min}$ at $37^{\circ} \mathrm{C}$, stained with $50 \mathrm{mg} / \mathrm{mL} \mathrm{PI}$ in the dark for $30 \mathrm{~min}$, and subjected to flow cytometry analysis. For each experiment, $5 \times 10^{3}$ cells were recorded. The obtained results were analyzed by Cell Quest software (Beckton Dickinson Immunocytometry Systems, USA).

\section{Cell apoptosis assay}

Apoptosis of MG63 cells was assessed by double staining using a FITC Annexin V/Dead Cell Apoptosis Kit (Invitrogen). Briefly, after corresponding treatments, cells were collected, washed with PBS, and re-suspended in binding buffer. Then, $5 \mu \mathrm{L}$ FITC-Annexin $\mathrm{V}$ and $5 \mu \mathrm{L}$ PI were added to the binding buffer, followed by incubation at room temperature in the dark for $15 \mathrm{~min}$. At least $2 \times 10^{4}$ cells were acquired using a flow cytometer 
(BD Bioscience, USA). Percentage of apoptotic cells was analyzed by FlowJo software (Tree Star, USA).

\section{Migration and invasion assays}

Migration of MG63 cells was determined by Transwell assay using the modified 24-well Boyden chambers (8- $\mu \mathrm{m}$ pore size, Corning Incorporated, USA). Cell invasion was assessed similarly with the cell migration assay, except that the transwell membranes were pre-coated with Matrigel (BD Biosciences). In brief, after relevant treatments, MG63 cells were re-suspended in $200 \mu \mathrm{L}$ FBS-free medium and seeded into the upper compartment. The lower compartment was filled with $600 \mu \mathrm{L}$ complete medium. The chambers were transferred to a humidified incubator at $37^{\circ} \mathrm{C}$ for $48 \mathrm{~h}$. After that, the cells on the upper surface of the inserts were removed carefully with a cotton swab, and the cells on the lower side of the filter were fixed in $100 \%$ methanol. Then, the fixed cells were stained with crystal violet solution and cells in five randomly chosen fields were counted microscopically.

\section{Quantitative reverse transcription PCR (qRT-PCR)}

Total RNAs in MG63 cells were isolated using a PureLink RNA Mini Kit (Thermo Fisher Scientific, USA). Then, RNA was quantified using a NanoDrop 1000 Spectrophotometer (Thermo Fisher Scientific) and reversetranscribed using the Universal cDNA Synthesis Kit II (Takara, China), following the manufacturer's protocol. After that, real-time PCR was performed using the ExiLENT SYBR ${ }^{\circledR}$ Green master mix (Takara) according to the supplier's protocol. The PCR conditions were as follows: $95^{\circ} \mathrm{C}$ for $10 \mathrm{~min}, 40$ cycles of $95^{\circ} \mathrm{C}$ for $10 \mathrm{~s}$, and $60^{\circ} \mathrm{C}$ for $1 \mathrm{~min}$. Fold-change of miR-133a was calculated by the $2^{-\Delta \Delta \mathrm{Ct}}$ method (19), and $\mathrm{U} 6$ expression was used to normalize the results.

\section{Western blot analysis}

Total proteins in MG63 cells were prepared in radioimmunoprecipitation (RIPA) buffer supplemented with protease inhibitor (Sigma, USA). Total proteins in cytoplasm of MG63 cells were isolated using Cytoplasmic Protein Extraction kit (Boster Biology Corporation). After centrifugation at $12,000 \mathrm{~g}$ at $4^{\circ} \mathrm{C}$ for $20 \mathrm{~min}$, protein content in the supernatants was determined by a bicinchoninic acid (BCA) assay kit (Thermo Scientific). Then, $40 \mu \mathrm{g}$ protein samples were separated by SDS-PAGE and transferred to nitrocellulose membranes, followed by blocking in fat-free milk. The membranes were incubated with primary antibodies against cyclinD1 (ab134175), p21 (ab109199), cytochrome C (ab90529), B cell lymphoma-2 (Bcl-2, ab196495), Bcl-2-associated X protein (Bax, ab182733), cleaved caspase-3 (ab2302), cleaved caspase-9 (ab2324), matrix metalloproteinase (MMP)-2 (ab97779), MMP-9 (ab137867), vimentin (ab137321), c-Jun (ab32137), phospho (p)-c-Jun (ab32385), $\beta$-actin (ab8229, all Abcam, Cambridge, UK), c-Jun N-terminal protein kinase (JNK; 9252), or p-JNK (9251, both Cell Signaling Technology, USA) at $4^{\circ} \mathrm{C}$ overnight. Membranes were then incubated with secondary antibody conjugated to HRP (goat anti-rabbit, ab205718, Abcam) at room temperature for $1 \mathrm{~h}$. Proteins in the membranes were detected using an enhanced Pierce chemiluminescence kit (Sigma), and the optical density of the bands was determined by ImageJ 1.47 software (National Institutes of Health, USA).

\section{Statistical analysis}

Data are reported as means \pm SE of three independent experiments. Statistical analysis was performed using GraphPad Prism 5 software (GraphPad, USA). Two-tailed Student's $t$-test was used for comparisons between two groups, and one-way analysis of variance (ANOVA) was used for comparisons among three groups. $\mathrm{P}<0.05$ was considered to be a significant difference.

\section{Results}

\section{APS repressed proliferation and induced apoptosis of MG63 cells}

Viability of MG63 cells after $0-20 \mathrm{mg} / \mathrm{mL}$ APS treatment was measured to determine the adequate concentration of APS. Cell viability was significantly reduced by 5-20 mg/mL APS treatment compared to non-treated cells $(P<0.01$ or $P<0.001)$ (Figure $1 A)$. The APS concentration of $10 \mathrm{mg} / \mathrm{mL}$ was chosen for subsequent experiments. Then, effects of APS on MG63 cell proliferation, cell cycle distribution, and apoptosis were explored. Percentage of BrdU positive cells in the APS treatment group was lower than that in the control group ( $P<0.01$, Figure 1B). The results of Figure $1 \mathrm{C}$ show that APS treatment significantly induced MG63 cell cycle $S$ phase arrest $(P<0.01)$. Meanwhile, the expression of CyclinD1 expression was down-regulated $(P<0.05)$ and the expression of $p 21$ was up-regulated $(P<0.01)$ after $10 \mathrm{mg} / \mathrm{mL}$ APS treatment (Figure 1D). As seen in Figure 1E, the percentage of apoptotic cells in the APS group was dramatically higher than that in the control group $(P<0.01)$. Accordingly, APS stimulation induced down-regulation of Bcl-2 and up-regulations of Bax, cleaved caspase-3, and cleaved caspase-9 in MG63 cells (Figure 1E). The expression of cytochrome $C$ in cytoplasmic of MG63 cells was also increased after APS treatment. These results indicated that APS repressed proliferation and induced apoptosis of MG63 cells.

\section{APS suppressed migration and invasion of MG63 cells}

Compared with the control group, the relative migration of MG63 cells was significantly decreased after $10 \mathrm{mg} / \mathrm{mL}$ APS treatment $(P<0.05$, Figure $2 A)$. The expression levels of MMP-2 and MMP-9 in MG63 cells 

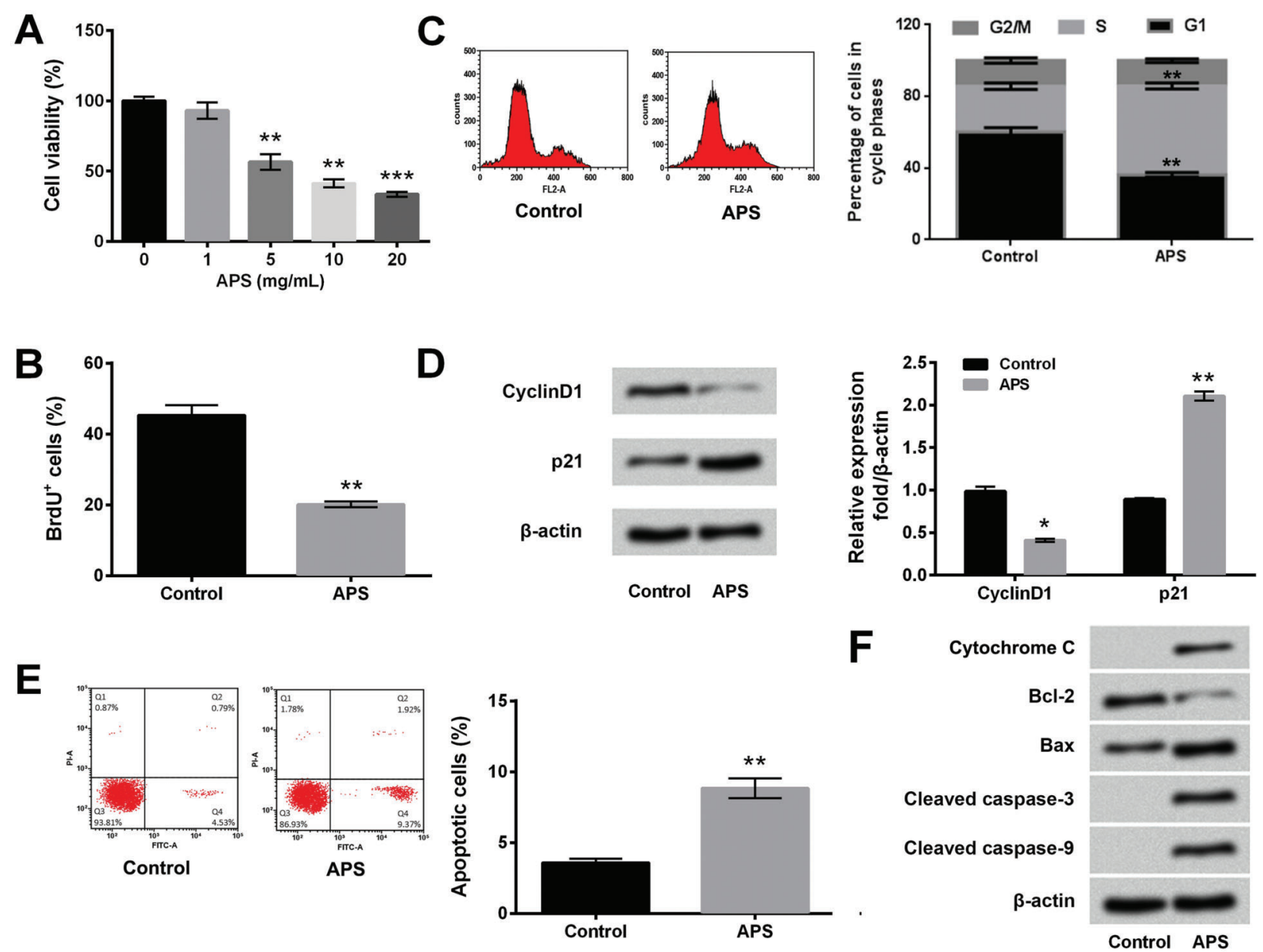

Figure 1. Astragalus polysaccharides (APS) reduced proliferation and induced apoptosis of MG63 cells. MG63 cells were treated by 1-20 mg/mL APS. Non-treated cells acted as control. A, Cell viability was detected by CCK-8 assay. B, Percentage of BrdU positive cells was measured by BrdU incorporation assay. C, Cell cycle distribution was assessed using PI staining and flow cytometry. $D$, Expression levels of proliferation-associated proteins were evaluated by western blot analysis. E, Percentage of apoptotic cells was determined by FITC Annexin V/Dead Cell Apoptosis kit and flow cytometry. F, Expression levels of apoptosis-associated proteins were evaluated by western blot analysis. Data are reported as means $\pm S E$ of three independent experiments. ${ }^{*} P<0.05 ;{ }^{*} P<0.01$; ${ }^{* * *} \mathrm{P}<0.001$ (ANOVA or $t$-test).

were down-regulated after APS stimulation $(P<0.05$ or $\mathrm{P}<0.01$, Figure 2B). Similarly, APS reduced invasion of MG63 cells $(P<0.05$, Figure $2 C)$ and down-regulated the expression of Vimentin $(P<0.01$, Figure 2D) in MG63 cells. These results suggested that APS inhibited migration and invasion of MG63 cells.

\section{APS induced up-regulation of miR-133a in MG63 cells}

As presented in Figure 3, the level of miR-133a in the APS treatment group was higher than that in the control group $(P<0.01)$, implying that miR-133a might participate in the anti-cancer effects of APS on MG63 cells.

\section{APS exerted anti-cancer effects on MG63 cells by up-regulating miR-133a}

The results in Figure $4 \mathrm{~A}$ show that miR-133a was significantly reduced after miR-133a inhibitor transfection compared with the NC group $(P<0.01)$. APS treatment-induced MG63 cell proliferation, migration, and invasion inhibition, cell apoptosis, and expression of proteins associated with these physiological processes were all significantly reversed by miR-133a knockdown $(\mathrm{P}<0.05$ or $\mathrm{P}<0.01$ ) (Figure $4 \mathrm{~B}-4 \mathrm{I})$ ). Taken together, these finding suggested that APS exerted anti-cancer effects on MG63 cells might via up-regulation of miR-133a. 

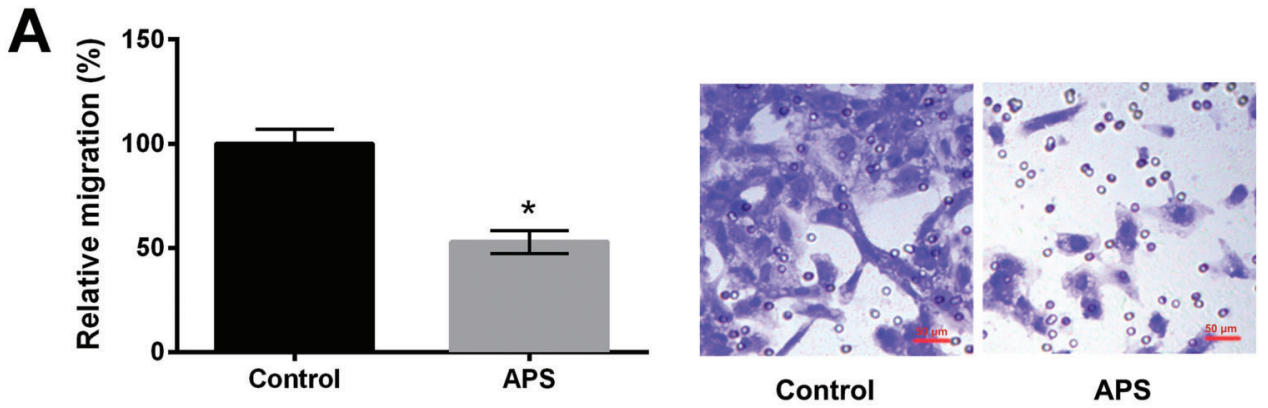

B
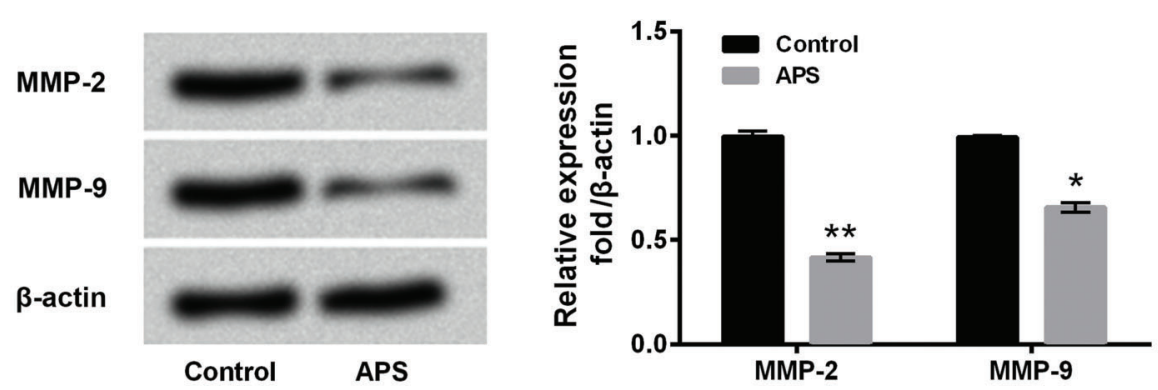

C
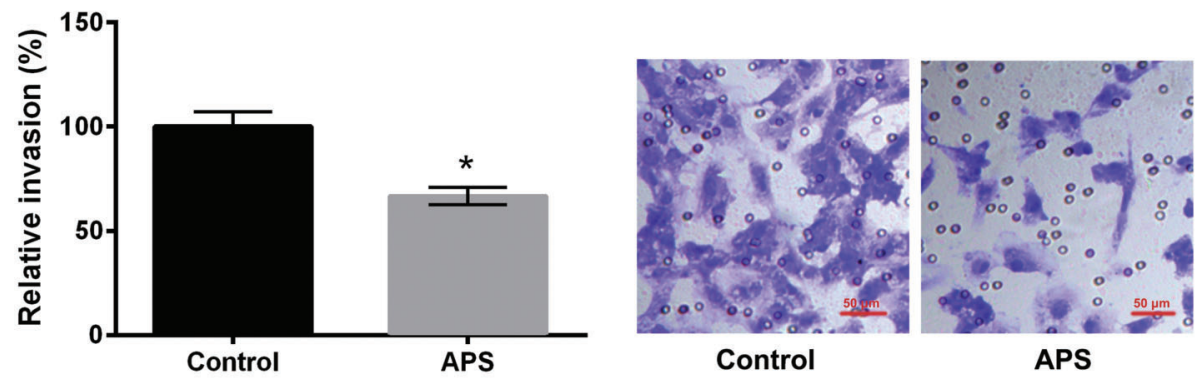

D

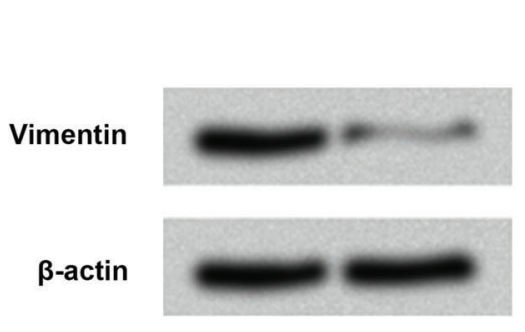

Control

APS

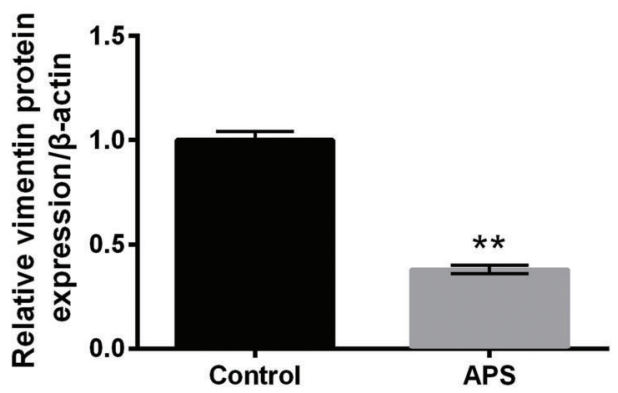

Figure 2. Astragalus polysaccharides (APS) suppressed migration and invasion of MG63 cells. MG63 cells were treated with $10 \mathrm{mg} / \mathrm{mL}$ APS. Non-treated cells acted as control. $A$, Cell migration was measured with the transwell migration assay. $B$, Expression levels of migration-associated proteins were assessed by western blot analysis. $C$, Cell invasion was detected with the transwell invasion assay. $D$, Expression of invasion-associated proteins were evaluated by western blot analysis. MMP: matrix metalloproteinase. Data are reported as means \pm SE of three independent experiments. ${ }^{*} \mathrm{P}<0.05 ;{ }^{* *} \mathrm{P}<0.01$ compared to control (t-test).

\section{APS inhibited JNK pathway in MG63 cells by up-regulating miR-133a}

Finally, the activation of JNK pathway in MG63 cells after APS treatment and/or miR-133a transfection was evaluated using western blotting. The results showed that the phosphorylated levels of JNK and c-Jun were both decreased after APS treatment $(\mathrm{P}<0.05$ or $\mathrm{P}<0.01$, Figure 5). Furthermore, the APS-induced phosphorylated 


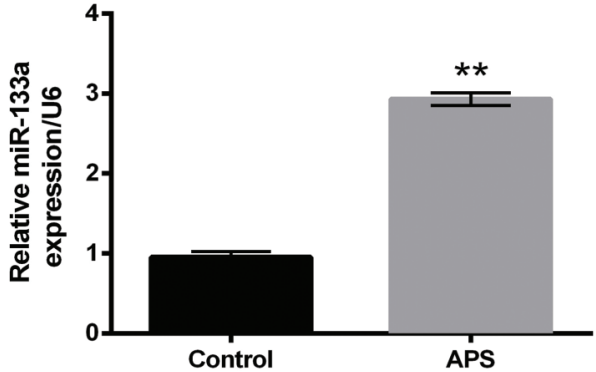

Figure 3. Astragalus polysaccharides (APS) induced up-regulation of miR-133a in MG63 cells. MG63 cells were stimulated with $10 \mathrm{mg} / \mathrm{mL}$ APS. Non-treated cells acted as control. Expression of miR-133a was determined by quantitative reverse transcription PCR. Data are reported as means \pm SE of three independent experiments. ${ }^{* *} \mathrm{P}<0.01$ ( $t$-test).

levels reduction of $\mathrm{p}$-JNK and $\mathrm{p}$-c-Jun were reversed by miR-133a inhibitor transfection (both $P<0.05$ ). These results illustrated that APS inactivated the JNK pathway through up-regulating miR-133a in MG63 cells.

\section{Discussion}

Tumor cells are able to thrive through promoted proliferation and inhibited apoptosis (20). Thus, inhibition of proliferation and inducement of apoptosis are considered two important therapeutic methods for tumor treatment, including OS treatment. BrdU is a thymidine analog that can be incorporated into DNA during replication; therefore, BrdU is widely used for labeling proliferating cells (21). Herein, the lower percentage of BrdU-positive cells after APS stimulation illustrated that APS could repress MG63 cell proliferation. CyclinD1 is a key mitogen sensor that promotes the conversion from the $\mathrm{G} 1$ phase to the $S$ phase and thereby promotes mitosis (22). p21 is the cyclin-dependent kinase inhibitor, which could regulate the G-phase checkpoint, induce cell cycle arrest, and impair DNA replication (23). In our study, the APS-induced down-regulation of cyclinD1 and up-regulation of p21 consolidated the anti-proliferative role of APS in MG63 cells. Flow cytometry results illustrated the pro-apoptotic role of APS. Moreover, APS down-regulated the anti-apoptotic Bcl-2 and up-regulated the pro-apoptotic Bax, leading to activation of caspase-9 and caspase-3. The expression of cytochrome in cytoplasm of MG63 cells was also increased after APS treatment. These alterations of apoptosis-associated proteins indicate that APS could induce MG63 cell apoptosis through mitochondrial and caspase-dependent pathways.

OS is a tumor with metastatic potential and metastasis is considered the leading cause of poor outcomes in OS patients $(24,25)$. Since migration and invasion are two major characteristics of metastasis, influence of APS on migration and invasion of MG63 cells was further explored. The extracellular matrix $(E C M)$ is a complex network that occupies the space between cells and maintains tissue integrity (26). Excessive degradation of ECM is a crucial process, by which cancer cells begin to migrate and invade (27). MMP-2 and MMP-9 are important molecules that degrade ECM and basement membrane (28). Vimentin, an intermediate filament protein, is widely accepted to be a metastasis marker and plays essential roles in the formation of invadopodia $(29,30)$. In our study, the down-regulations of MMP-2, MMP-9, and Vimentin reflected the inhibitory effects of APS on migration and invasion of MG63 cells, suggesting that APS exerted anti-cancer role in OS also by inhibiting cell migration and invasion.

MiR-133a has been reported as a tumor suppressor in several cancer types, such as glioma, colorectal cancer, etc. $(31,32)$. For OS, miR-133a down-regulation is associated to unfavorable prognosis in patients with OS (33). OS cell proliferation, invasion, and metastasis were all repressed by miR-133a (34). Another study also stated that miR-133a inhibited proliferation and induced apoptosis of OS cells (35). Thus, we supposed that there might be an interaction between miR-133a expression and APS stimulation. We found that miR-133a expression was up-regulated in APS treatment group. More importantly, miR-133a knockdown reversed the effects of APS on MG63 cell proliferation, apoptosis, migration, and invasion, as well as expression levels of associated proteins. These results indicate that APS possess antitumorous activity through up-regulating miR-133a in MG63 cells.

Fromigué et al. (36) reported the regulatory role of JNK in MMP-2 activity and invasion process in OS cells. c-Jun is a crucial mediator and it can be phosphorylated by JNK, followed by activation of MMP-2 promoter (37). Consequently, the phosphorylation of JNK and c-Jun was studied. Some miRs, including miR-223 (38), miR-127 (39), and miR-373 (40), have been found to be involved in the regulation of JNK pathway in OS cells. Herein, we proposed that miR-133a might also participate in the regulation of JNK pathway in MG63 cells. Thus, we also analyzed the activation of JNK pathway in MG63 cells after APS treatment and/or miR-133a inhibitor transfection. We found that JNK pathway was inhibited by APS, which might be a rational explanation for the downregulation of MMPs and inhibition of metastasis. We also found that APS-induced inactivation of JNK pathway was reversed by miR-133a knockdown in MG63 cells. These findings implied that APS exerted anti-cancer roles in MG63 cells by up-regulating miR-133a and then inactivating JNK pathway.

To summarize, we reported for the first time that APS exerted anti-tumorous activity in OS cells by inhibiting proliferation, migration, and invasion, and inducing apoptosis. In addition, we pointed out that miR-133a 
A

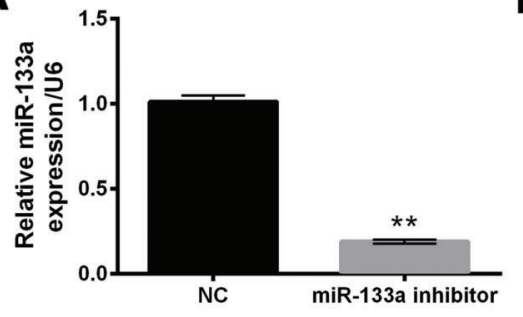

D
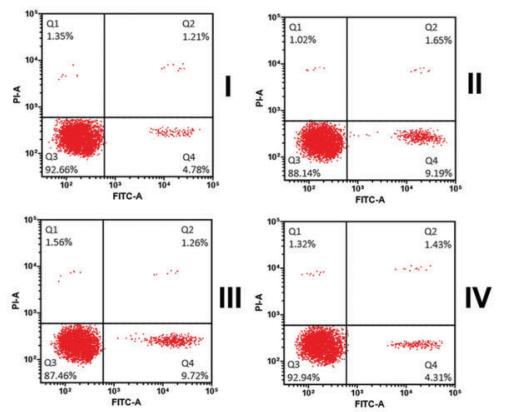

F

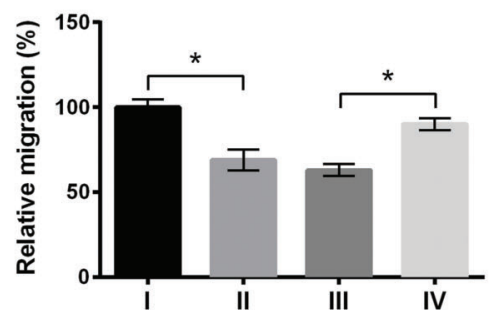

H

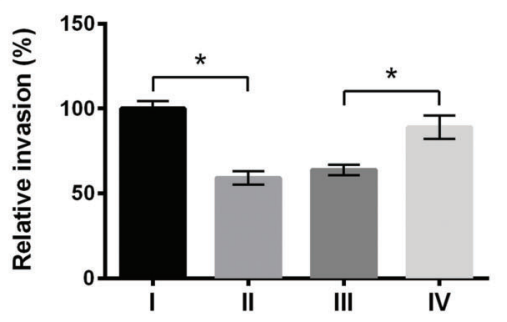

I: Control
B
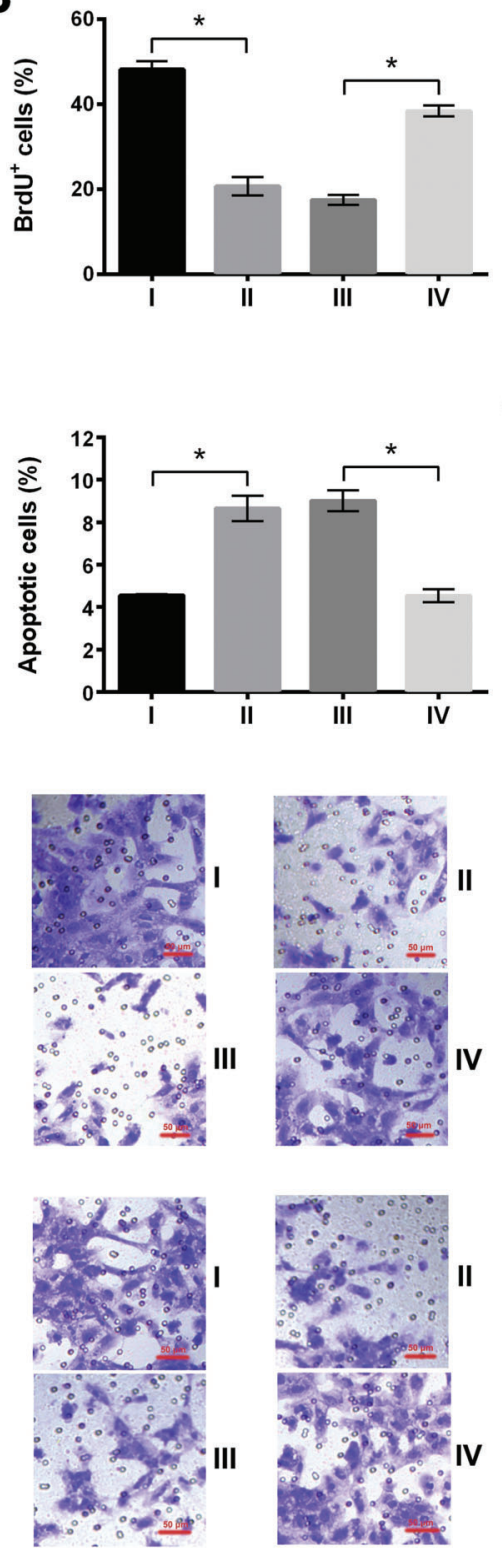

III: APS+NC
C

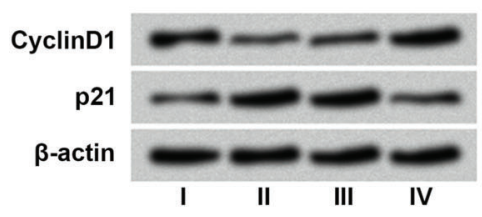

E
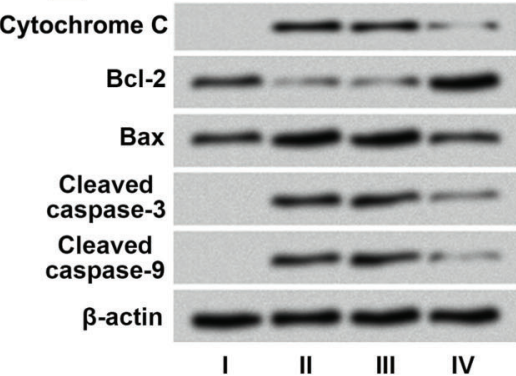

G

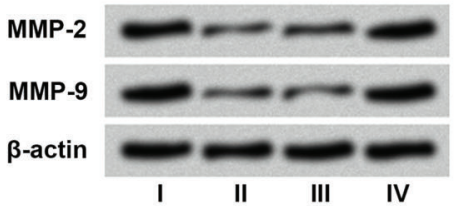

|

Vimentin

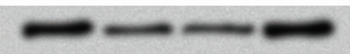

$\beta$-actin

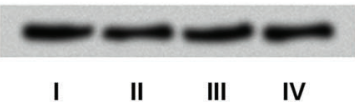

IV: APS+miR-133a inhibitor

Figure 4. Effects of Astragalus polysaccharides (APS) on MG63 cells were reversed by miR-133a inhibition. A, After miR-133a inhibitor transfection, the expression of miR-133a in MG63 cells was determined by quantitative reverse transcription PCR. Transfected and nontransfected cells were stimulated with $10 \mathrm{mg} / \mathrm{mL}$ APS. Non-treated cells acted as control (NC). B, Percentage of BrdU positive cells was detected by $\mathrm{BrdU}$ incorporation assay. $C$, Expression levels of proliferation-associated proteins were assessed by western blot analysis. $D$, Percentage of apoptotic cells was measured by flow cytometry. $E$, Expression levels of apoptosis-associated proteins were evaluated by western blot analysis. $F$, Cell migration was determined by transwell migration assay. $G$, Expression levels of migration-associated proteins were detected by western blot analysis. MMP: matrix metalloproteinase. $H$, Cell invasion was measured by transwell invasion assay. $I$, Expression of invasion-associated protein was evaluated by western blot analysis. Data are reported as means \pm SE of three independent experiments. ${ }^{*} \mathrm{P}<0.05 ;{ }^{* *} \mathrm{P}<0.01$ (ANOVA). 

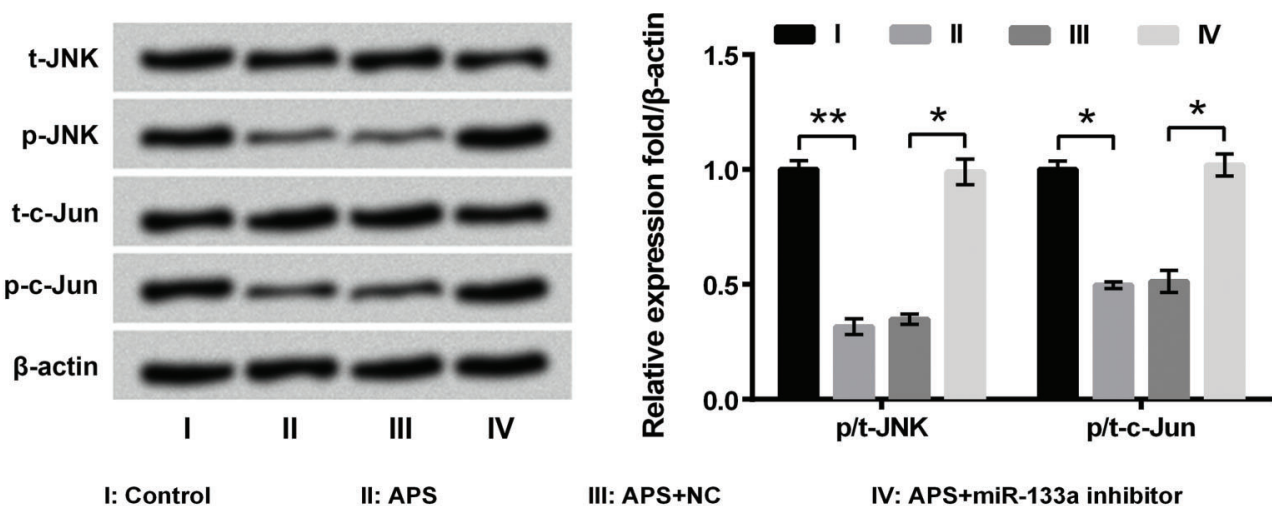

II: APS

III: APS+NC

IV: APS+miR-133a inhibitor

Figure 5. Astragalus polysaccharides (APS) inhibited JNK pathway through up-regulating miR-133a in MG63 cells. Transfected and non-transfected MG63 cells were stimulated with $10 \mathrm{mg} / \mathrm{mL}$ APS. Non-treated cells acted as control. Expression levels of proteins involved in the JNK pathway were assessed by western blot analysis. Data are reported as means \pm SE of three independent experiments. ${ }^{*} \mathrm{P}<0.05 ;{ }^{*} \mathrm{P}<0.01$ (ANOVA).

and JNK pathway were involved in the anti-cancer effects of APS on OS cells. Our study provides a theoretical basis for further exploring the treatment of OS using APS. More in vitro and in vivo studies are still needed.

\section{References}

1. Mirabello L, Troisi RJ, Savage SA. Osteosarcoma incidence and survival rates from 1973 to 2004: data from the surveillance, epidemiology, and end results program. Cancer 2009; 115: 1531-1543, doi: 10.1002/cncr.24121.

2. Dong $F$, Liu T, Jin H, Wang W. Chimaphilin inhibits human osteosarcoma cell invasion and metastasis through suppressing the TGF- $\beta 1$-induced epithelial-to-mesenchymal transition markers via PI-3K/Akt, ERK1/2, and Smad signaling pathways. Can J Physiol Pharmacol 2018; 96: 1-7, doi: 10.1139/cjpp-2016-0522.

3. Picci P. Osteosarcoma (osteogenic sarcoma). Orphanet $J$ Rare Dis 2007; 2: 6, doi: 10.1186/1750-1172-2-6.

4. Uzan VRM, Lengert AvH, Boldrini É, Penna V, ScapulatempoNeto C, Scrideli CA, et al. High expression of HULC is associated with poor prognosis in osteosarcoma patients. PloS One 2016; 11: e0156774, doi: 10.1371/journal.pone.0156774.

5. Bielack SS, Kempf-Bielack B, Delling G, Exner GU, Flege S, Helmke $\mathrm{K}$, et al. Prognostic factors in high-grade osteosarcoma of the extremities or trunk: an analysis of 1,702 patients treated on neoadjuvant cooperative osteosarcoma study group protocols. J Clin Oncol 2002; 20: 776-790, doi: $10.1200 / \mathrm{JCO} .2002 .20 .3 .776$.

6. Avnet S, Lemma S, Cortini M, Pellegrini P, Perut F, Zini $\mathrm{N}$, et al. Altered $\mathrm{pH}$ gradient at the plasma membrane of osteosarcoma cells is a key mechanism of drug resistance. Oncotarget 2016; 7: 63408-63423, doi: 10.18632/ oncotarget. 11503

7. Chou AJ, Gorlick R. Chemotherapy resistance in osteosarcoma: current challenges and future directions. Expert Rev Anticancer Ther 2006; 6: 1075-1085, doi: 10.1586/14737 140.6.7.1075.

\section{Acknowledgments}

This work was supported by Science and Technology Development Project of Qingdao Economic and Technological Development Zone (2014-1-78).

8. Chen W, Xia YP, Chen WJ, Yu MH, Li YM, Ye HY. Improvement of myocardial glycolipid metabolic disorder in diabetic hamster with Astragalus polysaccharides treatment. Mol Biol Rep 2012; 39: 7609-7615, doi: 10.1007/s11033012-1595-y.

9. Liu Y, Liu F, Yang Y, Li D, Lv J, Ou Y, et al. Astragalus polysaccharide ameliorates ionizing radiation-induced oxidative stress in mice. Int J Biol Macromol 2014; 68: 209-214, doi: 10.1016/j.ijbiomac.2014.05.001.

10. Guo Q, Sun X, Zhang Z, Zhang L, Yao G, Li F, et al. The effect of Astragalus polysaccharide on the Epstein-Barr virus Iytic cycle. Acta Virol 2014; 58: 76-80, doi: 10.4149/av_ 2014_01_76.

11. Lu J, Chen X, Zhang Y, Xu J, Zhang L, Li Z, et al. Astragalus polysaccharide induces anti-inflammatory effects dependent on AMPK activity in palmitate-treated RAW264.7 cells. Int J Mol Med 2013; 31: 1463-1470, doi: 10.3892/ijmm. 2013.1335.

12. Jiang JB, Qiu JD, Yang LH, He JP, Smith GW, Li HQ. Therapeutic effects of astragalus polysaccharides on inflammation and synovial apoptosis in rats with adjuvant-induced arthritis. Int J Rheum Dis 2010; 13: 396-405, doi: 10.1111/ j.1756-185X.2010.01555.x.

13. Yang B, Xiao B, Sun T. Antitumor and immunomodulatory activity of Astragalus membranaceus polysaccharides in H22 tumor-bearing mice. Int J Biol Macromol 2013; 62: 287-290, doi: 10.1016/j.ijbiomac.2013.09.016.

14. Huang WH, Liao WR, Sun RX. Astragalus polysaccharide induces the apoptosis of human hepatocellular carcinoma cells by decreasing the expression of Notch1. Int J Mol Med 2016; 38: 551-557, doi: 10.3892/ijmm.2016.2632. 
15. Bartel DP. MicroRNAs: genomics, biogenesis, mechanism, and function. Cell 2004; 116: 281-297, doi: 10.1016/S00928674(04)00045-5.

16. Li Z, Li Y, Wang N, Yang L, Zhao W, Zeng X. miR-130b targets NKD2 and regulates the Wnt signaling to promote proliferation and inhibit apoptosis in osteosarcoma cells. Biochem Biophys Res Commun 2016; 471: 479-485, doi: 10.1016/j.bbrc.2016.02.050.

17. Lu J, Song G, Tang Q, Yin J, Zou C, Zhao Z, et al. MiR-26a inhibits stem cell-like phenotype and tumor growth of osteosarcoma by targeting Jagged1. Oncogene 2017; 36: 231-241, doi: 10.1038/onc.2016.194.

18. Ke B, Ke X, Wan X, Yang Y, Huang Y, Qin J, et al. Astragalus polysaccharides attenuates TNF- $\alpha$-induced insulin resistance via suppression of miR-721 and activation of PPAR- $\gamma$ and PI3K/AKT in 3T3-L1 adipocytes. Am J Trans/ Res 2017; 9: 2195-2206.

19. Livak KJ, Schmittgen TD. Analysis of relative gene expression data using real-time quantitative PCR and the 2(-Delta Delta C(T)) Method. Methods 2001; 25: 402-408, doi: 10.1006/meth.2001.1262.

20. Raghunandan BN, Sanjai K, Kumaraswamy J, Papaiah L, Pandey B, Jyothi BM. Expression of human telomerase reverse transcriptase protein in oral epithelial dysplasia and oral squamous cell carcinoma: An immunohistochemical study. J Oral Maxillofac Pathol 2016; 20: 96-101, doi: 10.4103/0973-029X.180953.

21. Somkuwar SS, Fannon MJ, Staples MC, Zamora-Martinez ER, Navarro Al, Kim A, et al. Alcohol dependence-induced regulation of the proliferation and survival of adult brain progenitors is associated with altered BDNF-TrkB signaling. Brain Struct Funct 2016; 221: 4319-4335, doi: 10.1007/ s00429-015-1163-z.

22. $\mathrm{Li} Z$, Jiang $K$, Zhu $X$, Lin $G$, Song $F$, Zhao $Y$, et al. Encorafenib (LGX818), a potent BRAF inhibitor, induces senescence accompanied by autophagy in BRAFV600E melanoma cells. Cancer Lett 2016; 370: 332-344, doi: 10.1016/j.canlet.2015.11.015.

23. Gongpan P, Lu Y, Wang F, Xu Y, Xiong W. AS160 controls eukaryotic cell cycle and proliferation by regulating the CDK inhibitor p21. Cell Cycle 2016; 15: 1733-1741, doi: 10.1080/ 15384101.2016.1183853.

24. Zhang W, Morris J, Piperdi S, Guo Y, Ji T, Yang R, et al. Abstract 2182: Flavokawain A and B from kava extract exhibits low toxicity and up-regulates tumor suppressor miRNAs in human osteosarcoma cells. Cancer Res 2016; 76: 2182-2182, doi: 10.1158/1538-7445.AM2016-2182.

25. Wei X, Wang C, Ma C, Sun W, Li H, Cai Z. Long noncoding RNA ANRIL is activated by hypoxia-inducible factor- $1 \alpha$ and promotes osteosarcoma cell invasion and suppresses cell apoptosis upon hypoxia. Cancer Cell Int 2016; 16: 73, doi: 10.1186/s12935-016-0349-7.

26. Topalovski M, Brekken RA. The extracellular matrix of tumors: a focus on fibronectin and fibulin-5. In: Brekken RA, Stupack D, editors. Extracellular matrix in tumor biology. Cham: Springer International Publishing; 2017. p 1-15.

27. Jin C, Lin JR, Ma L, Song Y, Shi YX, Jiang P, et al. Elevated spondin-2 expression correlates with progression and prognosis in gastric cancer. Oncotarget 2017; 8: 10416-10424, doi: 10.18632/oncotarget.14423.
28. Wu YJ, Neoh CA, Tsao CY, Su JH, Li HH. Sinulariolide suppresses human hepatocellular carcinoma cell migration and invasion by inhibiting matrix metalloproteinase-2/-9 through MAPKs and PI3K/Akt signaling pathways. Int $\mathrm{J}$ Mol Sci 2015; 16: 16469-16482, doi: 10.3390/ijms 1607 16469.

29. Piotrowski-Daspit AS, Tien J, Nelson CM. Interstitial fluid pressure regulates collective invasion in engineered human breast tumors via Snail, vimentin, and E-cadherin. Integr Biol 2016; 8: 319-331, doi: 10.1039/C5IB00282F.

30. Qiu X, Cheng JC, Zhao J, Chang HM, Leung PC. Transforming growth factor-beta stimulates human ovarian cancer cell migration by up-regulating connexin43 expression via Smad2/3 signaling. Cell Signal 2015; 27: 19561962, doi: 10.1016/j.cellsig.2015.07.010.

31. Sakr M, Takino T, Sabit H, Nakada M, Li Z, Sato H. miR$150-5 p$ and miR-133a suppress glioma cell proliferation and migration through targeting membrane-type-1 matrix metalloproteinase. Gene 2016; 587: 155-162, doi: 10.1016/ j.gene.2016.04.058.

32. Li W, Chen A, Xiong L, Chen T, Tao F, Lu Y, et al. miR-133a acts as a tumor suppressor in colorectal cancer by targeting elF4A1. Tumour Biol 2017; 39, doi: 10.1177/10104 28317698389

33. Mirghasemi A, Taheriazam A, Karbasy SH, Torkaman A, Shakeri M, Yahaghi E, et al. Down-regulation of miR-133a and miR-539 are associated with unfavorable prognosis in patients suffering from osteosarcoma. Cancer Cell International 2015; 15: 86, doi: 10.1186/s12935-015-0237-6.

34. Chen G, Fang T, Huang Z, Qi Y, Du S, Di T, et al. MicroRNA133a inhibits osteosarcoma cells proliferation and invasion via targeting IGF-1R. Cell Physiol Biochem 2016; 38: 598-608, doi: 10.1159/000438653.

35. Ji F, Zhang H, Wang Y, Li M, Xu W, Kang Y, et al. MicroRNA133a, downregulated in osteosarcoma, suppresses proliferation and promotes apoptosis by targeting $\mathrm{Bcl}-\mathrm{xL}$ and Mcl-1. Bone 2013; 56: 220-226, doi: 10.1016/j.bone.2013. 05.020 .

36. Fromigué $\mathrm{O}$, Hamidouche $\mathrm{Z}$, Marie PJ. Blockade of the RhoA-JNK-C-Jun-MMP2 cascade by atorvastatin reduces osteosarcoma cell invasion. J Biol Chem 2008; 283: 3054930556, doi: 10.1074/jbc.M801436200.

37. Bian J, Sun Y. Transcriptional activation by $p 53$ of the human type IV collagenase (gelatinase A or matrix metalloproteinase 2) promoter. Mol Cell Biol 1997; 17: 6330-6338, doi: 10.1128/MCB.17.11.6330.

38. Tang Q, Yuan Q, Li H, Wang W, Xie G, Zhu K, et al. miR-223/Hsp70/JNK/JUN/miR-223 feedback loop modulates the chemoresistance of osteosarcoma to cisplatin. Biochem Biophys Res Commun 2018; 497: 827-834, doi: 10.1016/j.bbrc.2018.02.091.

39. Wang $Y$, Kong D. Knockdown of IncRNA MEG3 inhibits viability, migration, and invasion and promotes apoptosis by sponging miR-127 in osteosarcoma cell. J Cell Biochem 2018; 119: 669-679, doi: 10.1002/jcb.26230.

40. Liu Y, Cheng Z, Pan F, Yan W. MicroRNA-373 promotes growth and cellular invasion in osteosarcoma cells by activation of the PI3K/AKT-Rac1-JNK pathway: the potential role in spinal osteosarcoma. Oncol Res 2017; 25: 989-999, doi: $10.3727 / 096504016 \times 14813867762123$. 